\title{
Report of primary leiomyosarcoma of renal pelvis and literature review
} \author{
Bala Thirunavukkarasu ${ }^{4}$ \\ ${ }^{1}$ Department of Radiation Oncology, All India Institute of Medical Sciences, New Delhi 110029, India. \\ ${ }^{2}$ Department of Surgery, All India Institute of Medical Sciences, New Delhi 110029, India. \\ ${ }^{3}$ Department of Medical Oncology, All India Institute of Medical Sciences, New Delhi 110029, India. \\ ${ }^{4}$ Department of Pathology, All India Institute of Medical Sciences, New Delhi 110029, India.
}

Abhidha Malik ${ }^{1}$, Ritesh Kumar ${ }^{1}$, Abhishek Shankar $^{1}$, Sunil Chumber ${ }^{2}$, Sameer Bakhshi $^{3}$, Seema Kaushal $^{4}$,

Correspondence to: Dr. Abhidha Malik, Department of Radiation Oncology, All India Institute of Medical Sciences, New Delhi 110029, India. E-mail: dr.abhidha@gmail.com

How to cite this article: Malik A, Kumar R, Shankar A, Chumber S, Bakhshi S, Kaushal S, Thirunavukkarasu B. Report of primary leiomyosarcoma of renal pelvis and literature review. J Cancer Metastasis Treat 2017;3:111-5.

Article history:

Received: 05-02-2017

Accepted: 24-03-2017

Published: $30-06-2017$

Key words:

Primary,

leiomyosarcoma,

renal pelvis

\begin{abstract}
Primary sarcomas of kidney are exceptionally rare tumors, accounting for only $1-2 \%$ of all malignant tumors of kidney. Leiomyosarcoma (LMS) is the most common histological subtype among all renal sarcomas. The authors describe here a case of primary leiomyosarcoma of renal pelvis in a 50-year-old lady, presenting with flank pain. Based on triple phase cardio-electroencephalographic covariance tracing abdomen, presumptive diagnosis of renal cell carcinoma/renal sarcoma/neurogenic tumor was made and patient underwent radical nephrectomy. Microscopy reflected spindle cell tumor which showed strong positivity for desmin and smooth muscle actin with negative epithelial markers, thereby confirming the diagnosis of renal LMS. Owing to aggressive nature and low survival rates of LMS patient received adjuvant treatment in form of chemotherapy and radiotherapy. Patient is doing well 1 year post treatment.
\end{abstract}

\section{INTRODUCTION}

Primary sarcomas of kidney constitute $1-2 \%$ of all malignant tumors of kidney. ${ }^{[1]}$ LMS is most common histological subtype, accounting $60-70 \%$ of all sarcomas of kidney, commonly seen in females in 4th-6th decades. ${ }^{[2]}$ Radical nephrectomy remains the treatment of choice. ${ }^{[3]}$ The role of adjuvant treatment remains debatable due to paucity of data on treatment of this rare neoplasm. Herein, we report a case of a 50-year-old lady with leiomyosarcoma originating in renal pelvis along with relevant review of literature.

\section{CASE REPORT}

A 50-year-old postmenopausal lady, known case of hypothyroidism on T Thyroxin for 3 years, presented with diffuse dull aching paroxysmal pain in left flank of 2 months duration. On physical examination PORT 
scar, due to laproscopic cholecystectomy done 2 years back was visualized. No mass palpable. Triple phase contrast-enhanced computed tomography (CECT) scan of whole abdomen revealed [Figure 1], well defined retroperitoneal mass in left para-aortic location with anterior displacement of left renal vein. Neurogenic origin/mesenchymal tumor. Patient planned for wide local excision of the mass, intraoperatively the mass was adherent to left renal vein and feeder vein, therefore decision taken to perform left nephrectomy along with adrenalectomy. Postoperatively, gross examination of the specimen reveals greyish white tumor measuring $8 \mathrm{~cm} \times$ $4 \mathrm{~cm} \times 2 \mathrm{~cm}$, infiltration of the renal pelvis but not infiltrating into renal parenchyma. Renal sinuses, resected end of ureter and adrenal gland all were free of tumor. Microscopically tumor comprises of oval to spindle cells with moderate amount of cytoplasm and eosinophilic pleomorphic nuclei, tumor cells are arranged in interlacing fascicles and at places show cytoplasmic clearing, mitotic activity of $7-10 / \mathrm{hpf}$, less than $50 \%$ necrosis, FNCLC grade 2. Immunopositive for desmin and smooth muscle actin (SMA), whereas immunonegative for Pan CK, CD-34, EMA, Bcl2, S-100, MIC-2. Overall features were suggestive of leiomyosarcoma [Figure 2]. Post operative CECT of chest, abdomen and pelvis were within normal limits. Patient received 6 cycles of adjuvant chemotherapy with single agent injection adriamycin $25 \mathrm{mg} / \mathrm{m}^{2}$ day 1-3 followed by post operative radiotherapy to tumor bed to a dose of $50 \mathrm{~Gy} / 25 \# / 5$ weeks. Patient is doing well 1 year post treatment.

\section{DISCUSSION}

LMS are malignant neoplasm of smooth muscle origin. They are most commonly found in uterus, stomach, small intestine and retroperitoneum. ${ }^{[4]}$ LMS of renal origin are very rare and constitute only $0.12 \%$ of all malignant renal neoplasms. ${ }^{[5]}$ LMS of kidney was first described by Berry in 1919 but till date they have been reported only as case reports or as component

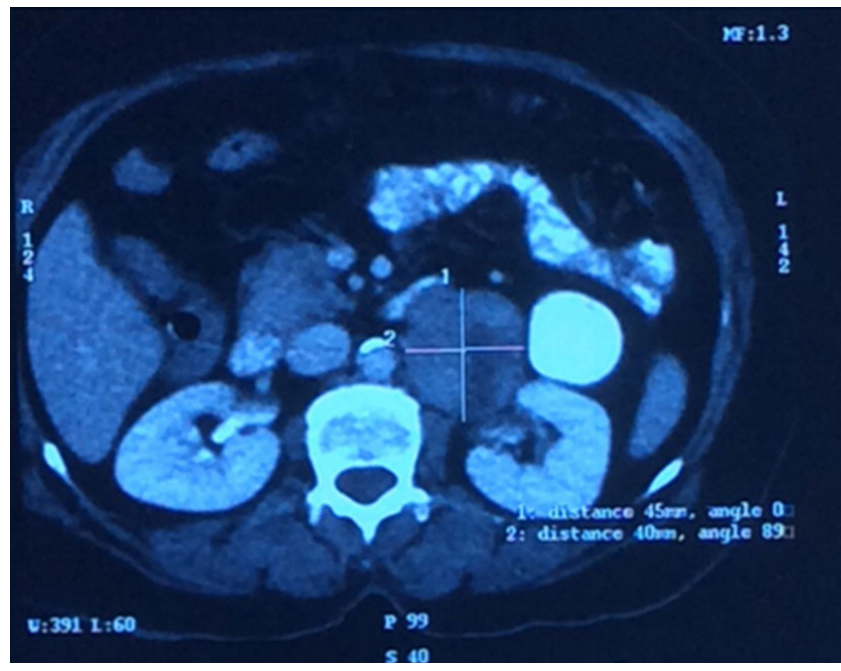

Figure 1: Contrast-enhanced computed tomography abdomen showing well defined retroperitoneal mass in left para-aortic location

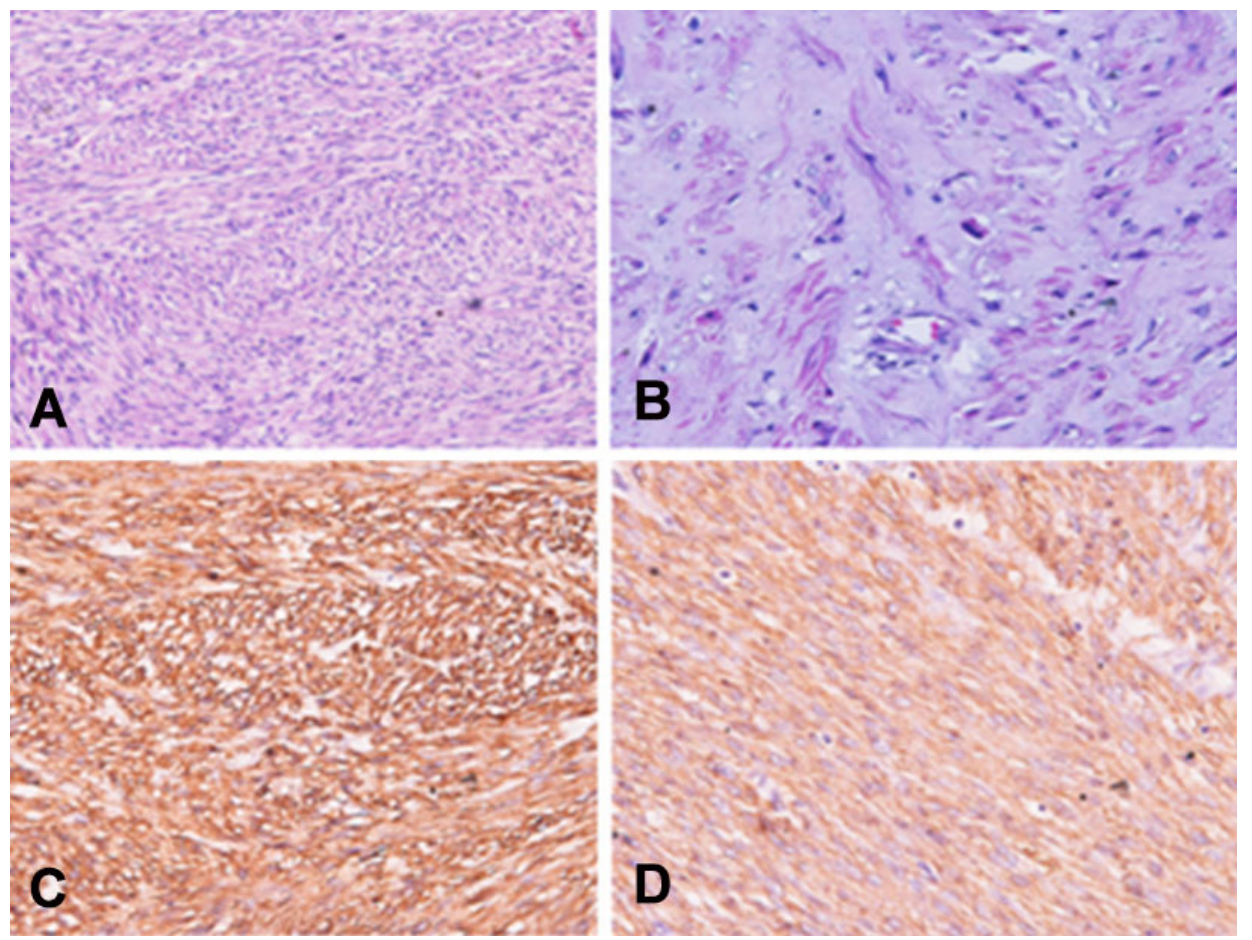

Figure 2: (A and B) Images comprising of oval to spindle tumor cells arranged in interlacing fascicles (A: 4x, B: 20x, HE); (C and D) images of desmin and smooth muscle actin immunopositivity, respectively $(20 \times, \mathrm{HE})$ 
Table 1: Summarizes clinic-radiological features, treatment and follow-up of previously reported cases of renal leiomyosarcoma in English literature in past 12 years

\begin{tabular}{|c|c|c|c|c|c|c|c|c|c|c|c|c|c|c|}
\hline No. & Ref. & Year & $\begin{array}{c}\text { Age } \\
\text { (year) }\end{array}$ & Gender & $\begin{array}{l}\text { Clinical } \\
\text { symptoms }\end{array}$ & Side & $\begin{array}{l}\text { CT } \\
\text { diag }\end{array}$ & $\begin{array}{l}\text { Size } \\
\left(\mathrm{cm}^{2}\right)\end{array}$ & Sx & $\begin{array}{l}\text { Adj } \\
\text { Rx }\end{array}$ & FU & LF & DF & $\begin{array}{c}\text { Site } \\
\text { of } \\
\text { DF }\end{array}$ \\
\hline 1 & [17] & 2004 & 54 & Male & $\begin{array}{c}\text { Abd } \\
\text { discomfort }\end{array}$ & Left & $\mathrm{RCC}$ & $8 \times 7.5$ & $\mathrm{~N}$ & No & 6 months & No & No & \\
\hline 2 & [18] & 2005 & 52 & Female & Incidental & Left & - & 2 & PN & No & 2 years & No & No & \\
\hline 3 & [19] & 2006 & 48 & Female & Flank mass & Right & $\mathrm{RCC}$ & $12.5 \times 10.5$ & $\mathrm{RN}$ & No & Unknown & - & - & \\
\hline 4 & [20] & 2006 & 44 & Male & Hematuria & Left & $\mathrm{RCC}$ & $5 \times 4$ & $\mathrm{RN}$ & No & 3 years & No & No & \\
\hline 5 & [21] & 2007 & 42 & Female & Incidental & Left & $\mathrm{RCC}$ & $5 \times 3$ & PN & No & Unknown & - & - & \\
\hline 6 & [1] & 2007 & 55 & Female & Abd pain & Right & RCC & $4 \times 2$ & NSS & No & 15 months & No & No & \\
\hline 7 & [8] & 2007 & 60 & Male & $\begin{array}{l}\text { Urinary } \\
\text { frequency }\end{array}$ & Right & $\mathrm{RCC}$ & $10 \times 8$ & $\mathrm{~N}$ & No & 6 months & No & No & \\
\hline 8 & [15] & 2007 & 55 & Male & Flank pain & Left & $\mathrm{RCC}$ & $3 \times 2.5$ & $\mathrm{RN}$ & Yes & 6.5 years & No & No & \\
\hline 9 & [6] & 2009 & 42 & Female & Flank pain & Right & $\mathrm{RCC}$ & 15 & $\mathrm{RN}$ & No & 7 months & No & No & \\
\hline 10 & [22] & 2009 & 71 & Male & Flank mass & Left & $\mathrm{RCC}$ & $13 \times 6.5$ & $\mathrm{RN}$ & Yes & 7 months & No & No & \\
\hline 11 & [23] & 2009 & 65 & Female & Flank mass & Right & $\mathrm{RCC}$ & $15 \times 11$ & $\mathrm{RN}$ & No & 1 year & No & No & \\
\hline 12 & [24] & 2010 & 55 & Female & Flank pain & Left & $\mathrm{RCC}$ & $20 \times 16$ & $\mathrm{RN}$ & No & Unknown & - & -- & \\
\hline 13 & [25] & 2011 & 57 & Female & Flank mass & Left & - & $25 \times 23$ & $\mathrm{RN}$ & No & 3 years & No & No & \\
\hline 14 & [26] & 2011 & 65 & Female & Flank pain & Right & - & $13 \times 11$ & $\mathrm{RN}$ & No & 15 months & No & No & \\
\hline 15 & [27] & 2012 & 74 & Female & Abd pain & Left & $\mathrm{RCC}$ & $8 \times 6$ & $\mathrm{RN}$ & No & 1 month & No & No & \\
\hline 16 & [28] & 2013 & 70 & Male & Flank pain & Right & $\mathrm{RCC}$ & 4 & $\mathrm{LN}$ & No & 2 months & No & Yes & Bone \\
\hline 17 & [29] & 2013 & 69 & Female & Flank mass & Right & RCC & $18 \times 15$ & $\mathrm{RN}$ & No & 5 years & No & No & \\
\hline 18 & [30] & 2013 & 20 & Male & Hematuria & Left & $\mathrm{RCC}$ & $7 \times 6$ & $\mathrm{LN}$ & No & 2 months & No & Yes & Lung \\
\hline 19 & [31] & 2014 & 65 & Female & Flank mass & Right & RCC & $18 \times 8$ & $\mathrm{~N}$ & No & 2 months & No & No & \\
\hline 20 & [14] & 2015 & 50 & Female & Flank pain & Left & - & $10 \times 6$ & $\mathrm{RN}$ & No & 1 year & No & No & \\
\hline 21 & [32] & 2015 & 39 & Male & Flank mass & Left & $\mathrm{RCC}$ & $16 \times 14$ & $\mathrm{RN}$ & No & 1 year & No & No & \\
\hline
\end{tabular}

Diag: diagnosis; Adj: adjuvant; Sx: surgery; Rx: treatment; FU: follow up; LF: local failure; DF: distant failure; Abd: abdomen; CT: computed tomography; RCC: renal cell carcinoma; N: nephrectomy; PN: partial nephrectomy; RN: radical nephrectomy; LN: laparoscopic nephrectomy; NSS: nephron sparing surgery

of larger series of renal sarcoma literature [Table 1].[6] Histogenesis of renal LMS is believed to be from renal capsule or smooth muscle fibers in renal pelvis or from the renal vessels. ${ }^{[7]}$

The renal LMS has preponderance in women, with women being twice more commonly affected than men and majority of patients presenting in 4th-6th decades of life. ${ }^{[8]}$ The cause of female preponderance is not fully known, but studies suggest that some malignancies are associated with genes located on $X$ chromosome that escape $X$ inactivation. ${ }^{\left[{ }^{[9}\right.}$ Renal LMS is found to occur equally on both sides and also bilaterally, however the etiology remains obscure. ${ }^{[10]}$

The patients of LMS usually presents with flank pain, hematuria and abdominal mass, thus mimicking renal cell carcinoma (RCC). It's difficult to differentiate between LMS and RCC. Ultrasound, tomography or magnetic resonance neither is able to differentiate between the two and diagnosis is usually made postoperatively. ${ }^{[11]}$ Because renal sarcoma is a rare condition; no effective treatment has yet been established. It is believed that surgery offers the best chance of cure therefore radical nephrectomy is treatment of choice, but recently partial nephrectomy has been shown to give good results in these patients. ${ }^{[12]}$
Histologically, leiomyosarcoma has to be differentiated from sarcomatoid RCC, leiomyoma and angiomyolipoma. Leiomyosarcoma can be differentiated from leiomyoma by presence of mitosis and necrosis in malignant tumor although cellular pleomorphism can be seen in both. Renal angiomyolipoma shows fascicles of smooth muscle cells admixed with mature fat and thick walled blood vessels. Sarcomatoid RCC forms the closest differential diagnosis of renal LMS. ${ }^{[13]}$

Diagnosis of sarcomatoid RCC can be made if typical RCC is seen somewhere in the tumor, so a thorough sampling of tumor is required to rule out any epithelial component of sarcomatoid RCC. Immunohistochemically tumor cells of leiomyosarcoma are positive for desmin, SMA calponin, $\mathrm{H}$ caldesmon and negative for CK, S-100 and HMB-45. The angiomyolipoma will show HMB-45 positivity while sarcomatoid variant of RCC will be CK positive. ${ }^{[14]}$

To make diagnosis of primary renal sarcoma the following criteria should be met: (1) the patient must not have or have had sarcoma elsewhere to rule out metastasis; (2) gross must be compatible with origin in kidney rather than involvement due to retroperitoneal sarcoma; (3) sarcomatoid variant of RCC must be excluded. ${ }^{[8]}$ 
Small size $<5 \mathrm{~cm}$, low histological grade and renal limited disease are associated with more favorable outcomes. Histological grade of tumor is assigned based on mitotic count, necrosis and nuclear pleomorphism. ${ }^{[8]}$ The most important prognostic factor is tumor free resected margin. Large size and metastasis to adjacent organs at the time of diagnosis makes the prognosis poor.

Adjuvant treatment in form of chemotherapy and radiotherapy has been tried differently by different people. Sharma et al. ${ }^{[15]}$ prescribed chemotherapy with mesna, adriamycin, ifosphamide and dacarbazine regimen and sandwich radiotherapy with a dose of $44 \mathrm{~Gy} / 22 \# / 4.5$ weeks to the renal bed and adjoining lymphatics. Beccia et al. ${ }^{[16]}$ prescribed vincristine $\left(1.4 \mathrm{mg} / \mathrm{m}^{2}\right)$ or cyclophosphamide $\left(700 \mathrm{mg} / \mathrm{m}^{2}\right)$ plus actinomycin $D\left(0.04 \mathrm{mg} / \mathrm{m}^{2}\right)$ to patients following surgery. As no randomized control trials have demonstrated their long term effects, treatment can be tailored individually. In our patient, we administered single agent doxorobicin ( $25 \mathrm{mg} / \mathrm{m}^{2}$ day $\left.1-3\right)$. Before administering treatment, we thoroughly explained our patient about potential benefits of adjuvant treatment, despite negative margin status and absence of metastasis. Our recommendations were based on high risk features like abdominal/retroperitoneal location, size greater than $5 \mathrm{~cm}$, high grade histology and presence of necrosis.

To conclude, renal leiomyosarcoma is a rare tumor should be differentiated from sarcomatoid variant of renal cell carcinoma and angiomyolipoma. Radical nephrectomy is treatment of choice but in spite of successful resection it usually shows an unfavorable prognosis. Aggressive treatment with adjuvant chemotherapy and radiotherapy can offer better results. Paucity of cases and absence of longterm follow up with controlled randomized studies is hampering definitive treatment protocols.

\section{Authors' contributions}

Conceptualisation of this work: R. Kumar, A. Malik

Providing all necessary information:

B. Thirunavukkarasu, A. Shankar

Jointly supervising the work: S. Chumber, S. Bakhshi, S. Kaushal

\section{Financial support and sponsorship None.}

\section{Conflicts of interest}

There are no conflicts of interest.

\section{Patient consent}

Patient consent was obtained as per institutional policy.

\section{Ethics approval}

The ethics approval was obtained from the institutional ethical committee for preparation and publication of this paper.

\section{REFERENCES}

1. Demir A, Yazici CM, Eren F, Türkeri L. Case report: good prognosis in leiomyosarcoma of the kidney. Int Urol Nephrol 2007;39:7-10.

2. Srinivas V, Sogani PC, Hajdu SI, Whitmore WF Jr. Sarcomas of the kidney. J Urol 1984;132:13-6.

3. Kavantas N, Pavlopoulos PM, Karaitianos I, Agapitos E. Renal leiomyosarcoma: report of three cases and review of the literature. Arch Ital Urol Androl 1999;71:307-11.

4. Weiss SW. Smooth muscle tumors of soft tissue. Adv Anat Pathol 2002;9:351-9.

5. Kendal WS. The comparative survival of renal leiomyosarcomas. Can J Urol 2007;14:3435-42.

6. Aiken W, Gibson T, Williams S, Gaskin D. Leiomyosarcoma of the kidney. West Indian Med J 2009;58:183-4.

7. Niceta P, Lavengood RW, Fernandes M, Tozzo PJ. Leiomyosarcoma of kidney. Review of the literature. Urology 1974;3:270-7.

8. Dhamne SA, Gadgil NM, Padmanabhan A. Leiomyosarcoma of the renal pelvis. Indian J Pathol Microbiol 2009;52:549-51.

9. Brown CJ, Greally JM. A stain upon the silence: genes escaping X inactivation. Trends Genet 2003;19:432-8.

10. Polianko NI. Leiomyosarcoma of both kidneys. Arkh Patol 1986;48:70-2. (in Russian)

11. Kurugoglu S, Ogut G, Mihmanli I, Korman U, Durak H. Abdominal leiomyosarcomas: radiologic appearances at various locations. Eur Radiol 2002;12:2933-42.

12. Lacquaniti S, Destito A, Candidi MO, Petrone D, Weir JM, Servello C, Pisanti F, Alcini E. Two atypical cases of renal leiomyosarcoma: clinical picture, diagnosis and therapy. Arch Ital Urol Androl 1998;70:199-201.

13. Grignon DJ, Ayala AG, Ro JY, el-Naggar A, Papadopoulos NJ. Primary sarcomas of the kidney. A clinicopathologic and DNA flow cytometric study of 17 cases. Cancer 1990;65:1611-8.

14. Srivastava P, Prasad R, Khanna G. Primary leiomyosarcoma of kidney: a rare case report. Muller J Med Sci Res 2015;6:157-9.

15. Sharma D, Pradhan ES, Aryya NC, Shukla VK. Leiomyosarcoma of kidney: a case report with long term result after radiotherapy and chemotherapy. Int Urol Nephrol 2007;39:397-400.

16. Beccia DJ, Elkort RJ, Krane RJ. Adjuvant chemotherapy in renal leiomyosarcoma. Urology 1979;13:652-4.

17. Minami H, Ueki O, Tanaka T, Nishida H, Hashimoto T, Kawaguchi K Case of leiomyosarcoma of the renal pelvis. Int J Urol 2004;11:122-4.

18. Cocuzza M, Arap S, Lucon AM, Saldanha LB. Renal Leiomyosarcoma treated with partial nephrectomy. Clinics (Sao Paulo) 2005;60:345-6.

19. Adhikari RC, Sayami G, Dali S, Shrestha HG. A case of leiomyosarcoma of the kidney. J Inst Med 2006;28;74-6.

20. Kartsanis G, Douros K, Zolota V, Perimenis P. Case report: leiomyosarcoma of the renal pelvis. Int Urol Nephrol 2006;38:211-3.

21. Chung YG, Kang SC, Yoon SM, Han JY, Seong DH. Leiomyosarcoma arising from the blind end of a bifid renal pelvis. Yonsei Med $J$ 2007;48:557-60.

22. Dubey A, Koul R. A rare case of renal sarcoma with the review of literature. Int J Nephrol 2009;6:1-5.

23. Choudhury M, Singh SK, Pujani M, Pathania OP. A case of Leiomyosarcoma of kidney clinically and radiologically misdiagnosed as renal cell carcinoma. Indian J Cancer 2009;46:241-3.

24. Venkatesh K, Lamba SM, Niveditha SR, Krishnagiri C, Babu 
S. Primary leiomyosarcoma of the kidney. Patholog Res Int 2010;2010:652398.

25. Azizun-Nisa, Hasan SH, Raza Y. Primary renal leiomyosarcoma. $J$ Coll Physicians Surg Pak 2011;21:713-4.

26. Ellouze S, Abid N, Kossentini M, Gouiaa N, Charfi S, Mhiri N, Boudawara T. Leiomyosarcoma of the kidney. Clin Genitourin Cancer 2011;9:68-9.

27. Pong YH, Tsai VFS, Wang SM. Primary leiomyosarcoma of the kidney. Formasan J Surg 2012;45:124-6.

28. Valery JR, Tan W, Cortese C. Renal leiomyosarcoma: a diagnostic challenge. Case Rep Oncol Med 2013;2013:459282.

29. Beardo P, José Ledo M, Jose Luis RC. Renal leiomyosarcoma. Rare Tumors 2013;5:e42.

30. Cho EY, Yoon JH, Kim W. Leiomyosarcoma of the renal pelvis: report of a case and review of the literature. OMICS J Radiol 2013;3:154.

31. Babu S, Singhai A, Hussain N, Singh V. Renal leiomyosarcoma -- a rare entity. J Case Rep 2014;4:29-32.

32. Bavikar R, Deshmukh S. Primary leiomyosarcoma of kidney in a young male treated with partial nephrectomy -- a case report. Sarcoma Res Int 2015;2:1013. 